\title{
Commentary: Can partial sinus replacement replace standard valve-sparing replacement?
}

\author{
Ho Jin Kim, MD, and Joon Bum Kim, MD, PhD
}

\footnotetext{
From the Department of Thoracic and Cardiovascular Surgery, Asan Medical Center, University of Ulsan College of Medicine, Seoul, Republic of Korea.

Disclosures: Authors have nothing to disclose with regard to commercial support.

Received for publication July 19, 2019; accepted for publication July 22, 2019; available ahead of print Sept 17, 2019.

Address for reprints: Joon Bum Kim, MD, PhD, Department of Thoracic and Cardiovascular Surgery, Asan Medical Center, University of Ulsan College of Medicine, 88, Olympic-ro 43-gil, Songpa-gu, Seoul, 05505, Republic of Korea (E-mail: jbkim1975@amc.seoul.kr).

J Thorac Cardiovasc Surg 2020;159:1187-8

0022-5223/\$36.00

Copyright (c) 2019 by The American Association for Thoracic Surgery

https://doi.org/10.1016/j.jtcvs.2019.07.061
}

In this issue of the Journal, Irimie and colleagues ${ }^{1}$ report their single-center experience of 100 consecutive patients presenting with acute type A aortic dissection who received operation with an aortic root remodeling technique (selected sinus replacement [SSR]) between 2001 and 2018. Depending on the intraoperative observation of dissected sinus, the patients underwent replacement of 1 $(n=62), 2(n=32)$, or $3(n=6)$ aortic sinuses. The noncoronary sinus was the most commonly replaced, in 97 patients, followed by the right coronary sinus $(n=39)$ and the left coronary sinus $(n=9)$. Surgical outcomes were excellent, with only $1 \%$ operative mortality $(\mathrm{n}=1)$, no aortic valve or root reintervention and no significant (grade $2+$ ) aortic insufficiency (AI) during a mean follow-up of $70 \pm 50$ months. The freedoms from all-cause death were $89.4 \%$ and $68.8 \%$ at 5 and 12 years, respectively.

This is another study of their single-center experiences that suggests the feasibility of SSR in the high-risk patient population. ${ }^{2,3}$ Irimie and colleagues ${ }^{1}$ are to be congratulated for demonstrating excellent long-term outcomes of their expeditious surgical strategy to treat acute type A aortic dissection, in which the decision to undertake this technique has been uniformly maintained throughout their 19-year experience. As described by Irimie and colleagues, ${ }^{1}$ the SSR technique was used in 100 of 170 patients presenting with root-involving acute aortic dissection during the study period, including $77 \%$ of the patients operated on by a single expert surgeon. Accordingly, the favorable surgical outcomes in this study may also be attributable to patient selection and the surgical expertise.

Of note, SSR was used even in 7 patients with Marfan syndrome in the study. In their previous report, ${ }^{3}$ this group demonstrated excellent surgical outcomes after SSR at a follow-up of $6.1 \pm 3.1$ years in the patients with marfanoid characteristics (aged $43 \pm 11$ years). As argued by the authors, ${ }^{3}$ dilated sinotubular junction and pathologic valve cusps may be more responsible for the development AI close follow-up.

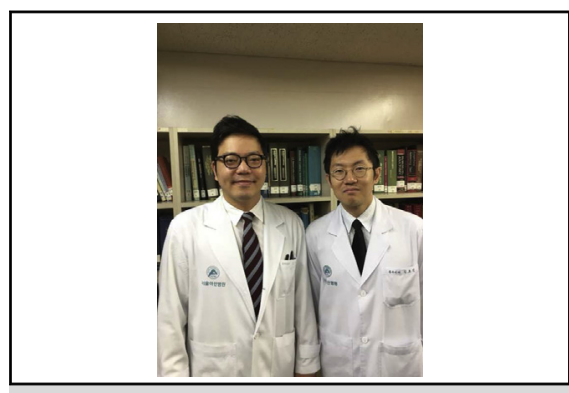

Joon Bum Kim, MD, PhD (left), and Ho Jin Kim, MD (right).

\section{Central Message}

We discuss performing a modified aortic root remodeling technique in patients with acute type A aortic dissection.

See Article page 1176.

than a dilated aortic annulus. It is well known, however, that the aortic root is the primary location where aortic catastrophe occurs in individuals with connective tissue disorder. Aortic root replacement, preferentially by standard valve-sparing technique, thus happens to be required in the majority of such individuals during their lifetime to prevent fatal aortic events. In addition, there is a growing body of evidence indicating that late root aneurysmal progression is common even in aortic sinuses of seemingly normal size that are left unreplaced during any types of root-preserving procedures in patients with connective tissue diseases. ${ }^{4}$ This leaves the chance of second operation as a consequence. In this regard, even if we agree with the arguments of Irimie and colleagues ${ }^{1}$ postulating the limited contribution of dilated root below the sinotubular junction to the development of AI, the fate of an unreplaced aortic sinus still remains concerns for late pathologic dilation in patients with connective tissue disease, thus mandating lifelong

As addressed by Irimie and colleagues, ${ }^{1}$ proper sizing of the aortic graft during SSR in the setting of acute type A aortic dissection is challenging. To raise the same issue in valve-sparing root reimplantation, they gave an example of severe downsizing of the aortic annulus resulting in AI, which is probably not a good example for experts who deal with such procedures. Although repair failure from improper graft sizing may occur with either of the techniques, we presume that SSR would still not make it easy 
to standardize the sizing of the graft and the tailoring of sinus patches. Perhaps newcomers to this technique may require a steep learning curve to achieve confident and reproducible surgical outcomes. This issue needs demonstration from further studies from other sites worldwide.

\section{References}

1. Irimie V, Atieh A, Kucinoski G, Jankulovski A, Zacher M, Urbanski PP Long-term outcomes after valve-sparing anatomical aortic root reconstruction in acute dissection involving the root. J Thorac Cardiovasc Surg. 2020;159: 1176-84.e1.

2. Urbanski PP, Jankulovski A, Doldurov K, Zhan X, Sodah A, Zacher M, et al. Reconstructive aortic valve surgery in the elderly: techniques and outcomes. J Thorac Cardiovasc Surg. 2018;155:1414-20.

3. Urbanski PP, Jankulowski A, Morka A, Irimie V, Zhan X, Zacher M, et al. Patienttailored aortic root repair in adult marfanoid patients: surgical considerations and outcomes. J Thorac Cardiovasc Surg. 2018;155:43-51.e1.

4. Park SJ, Kim JB, Chung CH. Isolated aortic root dilatation following sinotubular junction reduction using prosthetic rings. Interact Cardiovasc Thorac Surg. 2012; 14:680-2. 